
www.globaljournalseries.com, Email: info@globaljournalseries.com

\title{
REVIEW OF PARADIGM SHIFT IN BUILDING CONSRUCTION OCCASIONED BY CLIMAGE CHANGE
}

\author{
ABUGU NKECHINYERE ANTHONIA, YERO AHMED BELLO, IRENE AMAHAGBOR MACAULAY AND ODELE \\ MUYIWA OLIATAN,
}

(Received 26 April 2021; Revision Accepted 24 May 2021)

\begin{abstract}
The solution to climate change demands new strategies in building sector. Thus, a review of existing literature was conducted to find out the new thinking in building sector in relation to climate change. The objectives were to: examine the relationship between climate change and building construction; identify paradigm shifts in building policies as a response to climate change and to find out climate change mitigation and adaptation strategies in the building sector. These were achieved through the review of literature published in the era of the recent global climate change from late 90 s to date. Selection of paper was based on relevancy to the topic and date of publication. Preference was given to papers that link climate change with building sector, especially those that portray paradigm shift. Result showed that there are strong link between climate change and the building sector. As all previous reports reviewed revealed that climate change adversely affect building, a good number also argued that building construction is responsible for climate change mainly in terms of energy use and surface transformation/exposure. Although, there seems to be conflicting ideas on cause and effects between climate change and building construction, there is a general agreement that climate change affects building sector. Scholars also agree on integration of climatic parameters in building sector. Climate change has become a basis for policy reform in the building sector as many studies recommended knowledge and inclusion of climatic parameters in building planning, design, construction and use. Mitigation and adaptation of buildings to flood and extreme temperature were the common concerns of most studies. Raising of floor, use of local materials, orientation of building in accordance to sun and wind direction are among the mitigation and adaptation options for building construction in the face of changing climate.
\end{abstract}

KEYWORDS: Climate change, Building construction, paradigm shift, sustainability, climate adaptation

\section{INTRODUCTION}

Climate change has become a nightmare to both the developed and developing countries. The current threatening global climate change call for paradigm shift in building construction in developing countries. While the developed countries are retrofitting and remodeling for adaptation, the developing countries are to plan and implement building construction in accordance to present and future climatic predictions. It is time to design and construct buildings in line with climatic features. Though the developed countries have more capacity to mitigate and adapt to climate change, the developing countries can incorporate the climate extremes in planning and implementing development. Building professional are recently undergoing paradigm shift in design and implementation of building (Turnbull, et al, 2020).
The current emphases is not just aesthetic but resilient and adaptability to extreme climate events like flood, erosion, windstorm due to rising temperature and sea level rise (climate change).Flooding and windstorm events around the world produced a heightened sense of the need to better plan and design buildings and infrastructure to reduce vulnerability to climate extreme events.

According to Stephen et al., (2014) recent major natural disasters and their impacts on national and global economies have heightened awareness and spurred activity to improve the resilience of buildings. Similarly, Mona, (2017) opined that building professionals and designers need to incorporate strategies that consider climate change within their region. There is general agreement that the building construction sector is causally related to many of the climatic and other environmental challenges that we face today

Abugu Nkechinyere Anthonia, Geography Department Nasarawa State University Keffi, Nigeria

Yero Ahmed Bello, Faculty of Natural and Applied Sciences Nigerian Army University BIU

Irene Amahagbor Macaulay, Geography Department Nasarawa State University Keffi, Nigeria

Odele Muyiwa Oliatan, Geography Department Nasarawa State University Keffi, Nigeria 
(Emmanuel, 2009; Stephen et al., 2014; Bello, 2017). Thus, there is need for paradigm shift and policy intervention globally and regionally. Consequently, researches are being conducted on how to combat climate disasters through building designs and construction. Thus, there are new ideas on building design and construction. Therefore, there is need to review what is new in building construction in relation to climate change. Objectives were to pinpoint the relationship between climate change and building construction and then highlight the paradigm shifts in building policies and approaches as a response to climate change Thus, answers were provide for the following research questions: what are the relationships between climate change and building construction? What are the paradigm shifts in building policies as a response to climate change? And what are the climate change and adaptation options in the building sector?

\section{MATERIALS AND METHODS}

Mixed (qualitative and quantitative) methods were used in this study. However, it is mainly qualitative due to its descriptive nature. Over five hundred (500) research articles related to the topic were gathered and sorted for review. Out of which two hundred and thirty (230) representing about $46 \%$ were considered suitable, based on contextual and temporal scope of the study. On the basis of context, article must be on climate change and building construction, climate change adaptation and building infrastructure, building sustainability and climate change. On the other hand, preference was given to articles published in 2007 and upwards. This is because 2007 was when the fourth Intergovernmental Panel on Climate Change (IPCC) assessment report declared that climate change is an issue to be taken seriously. However, articles must not be published before late 19th century as scientists generally regard the later part of the 19th century as the point at which human activity started influencing the climate. Review was also conducted in two sections based on the study objectives.

\section{REVIEW OF LITERATURE}

\section{The relationship between climate change and} building construction

According to a report by Ministry of the Environment and Food of Denmark / Environmental Protection Agency (2020) building construction is both a causal factor of climate change and victim of climate change. Studies showed that climatic condition is vital in building design and construction. For instance, Zareaian and Zadeh, (2013) explained that the existence and awareness of the construction site of climatic parameters includes the amount and type of temperature, humidity, wind speed and direction, harmful environmental incidents including heavy showers, heavy weed, local changeability, glacial time, heavy snow and so on are paramount to building sustainability. Similarly, Emmanuel (2009) stated that it is necessary to study the climatic condition before a building could be design. It is considers that these items, mainly great values, would result in strength and sustainability of the building compared to undesirable provincial climate events and causes the fall energy loss at the time of exploitation. In line with Emmanuel (2009), Mona (2017) emphasized that knowledge of climate factors should be employed in building design and construction.

It has been argued that building decisions have a long time effect on the environment due to both the economic and physical values of buildings (Wilby, 2007). Though, the level of these effects and impacts on buildings depend on the locations of such buildings (Camilleri and Jaques, 2001; Crawley, 2008). Mohammed and Gayan, (2014) noted that the skill of handling projects in such extreme hot weather conditions has a vital role to play in future planning and preparation of site activities. Akanni, (2014) also opined that concept of sustainable construction might be defected when a good philosophy and successful management of the effect of environmental factors would determine the performance of such projects. Ugochukwu (2020) has it that buildings are usually designed to suit a specific climate, but their lifespan is often not more than a century.

Umoh, (2000) stressed that climatic regimes has long been recognized as a function of building houses. In the same vein, Camilleri et al., (2001) was of the opinion that the change in climate is expected to have impact on many aspects of building performance. Thus, it was advised that there is need to identify what impacts climate change may they have on buildings, how serious they could be and what action (if any) could be taken to ensure that performance of building is not compromised.

Several studies emphasized on the effects of climate change on building sector. For examples: Camilleri et al., (2010) lamented that climate change posed several challenges to many aspects of building performance in New Zealand. For each climate scenario, relevant aspects of building performance were tested to determine if there is likely to be a major impact. Where significant impacts were identified, they were studied in detail and quantified where possible. A risk-profiling tool was formulated to cover the risk/severity of the most significant climate change impacts, which included flooding, tropical cyclones and overheating. Modifying the strategies was developed for each climate change impact, with different strategy appropriate for each impact. Mitigation of greenhouse emissions was also addressed.

Yi et al., (2016) investigated the reliability of climate change to influence high rise building. Several sampling methods were utilized to estimate the extreme wind speed. They are, Kernel Density Estimation; Anemometer, Bootstrap Re-sampling Method and Monte Carlo Simulation etc. The wind speed usually has a linear relation to the daily mean temperature. Climate change can be considers to help do a rough approximation of the future wind speed. Onkangi et al., (2018) noted that infrastructure is very vulnerable structurally and financially to extreme weather conditions and events. Using vulnerability and adaptation indicators in the assessment tool, the extent of integration of climate knowledge in planning and implementing infrastructure projects in Kenya was evaluated. The findings indicated that there is great need to initiate early warning systems, incorporate rigorous risk assessments to determine infrastructure vulnerability levels, integrate adaptation measures and strengths for infrastructure and buildings to continue functioning in a changing 
planet, and avert retrogression and mark-timing development wise.

Furthermore, Few et al., (2007) stated that climate change on building identified the following impact such as: mean climatic conditions, increase in the degree of variability and shifts in the ecosystem and increased frequencies of weather elements.

Audrius and Arvydas (2017) evaluated that climate change is expected to have an influence on the energy performance of a residential building in Kaunas, Lithuania, basically due to changes in heating and cooling demand. The temperature data predict of IPCC (Intergovernmental Panel on Climate Change) typically concentrates pathways (RCP) 2.6 and RCP 8.5 were used for the periods of the 2020s (near subsequent) 2050s (middle subsequent) and 2080s (far subsequent), incorporated into hourly Energy Plus. Climate averages of over 30 year period were evaluated. The overall energy consumption shows that the result is small. Changes were detected in all scenarios and periods, from a drop by $8.5 \%-10.3 \%$ in total consumption in the 2020s under RCP2.6 scenario to $26.7 \%-29.6 \%$ decrease in case of the 2080s RCP8.5 scenario (the decrease by $15 \%-15.6 \%$ was observed under RCP8.5 scenario). The number of days when space heating is required decreased due to the sensational decrease, while a slightly increase of a cooling load in a modeled house still does not make it effective over a heating load.

Fanchao et al.,(2017) posited that climate plays an essential role in heating energy consumption of buildings because of the right parallel in between the changes in climate conditions and space heating. The Transient System Simulation Program Software was used to affect the heating loads of office buildings to compute the impact in Shanghai, Tianjin and Harbin, and three major climate zones were describe. The implementation of stepwise multiple linear regression determines the impact on heating energy consumption as the key climatic parameters. Dry bulb temperature (DBT) showed that the results is the dominant climatic parameter that influence the building heating loads in all three climate zones across china due to the heat period at daily, monthly, and yearly scales (R2 $\geq 0.86)$. Climate endless warming comes in with the winter over the past 50 years, the heat loads decreased by 14.2, 7.2, and 7.1 $\mathrm{W} / \mathrm{m} 2$ in Shanghai, Tianjin and Harbin, respectively; climate zone noting that the decrease rate in severe cold is more possible.

According to Bello et al., (2017), climate agents play an important role in the deterioration of building fabric, and a change in climate is expected to have a significant effect on deterioration.

There are also prominent views on the impacts of buildings on climate. Aliyu, (2010), for instance, noted that the building industry is a major source of greenhouse gases (GHGs); as giant consumer of natural resources such as forests, solid minerals and water, as well as, the role of poor designing in compounding health risks and excessive consumption of energy. However, according to a report by Ministry of the Environment and Food of Denmark / Environmental Protection Agency, (2020), buildings are mostly vulnerable, because all the climate change indicators such as bush fires, hurricane, flood and other adverse effects have huge consequences for the effective functionality of buildings. What this means is an intertwined interface between buildings and the natural environment and climate change (IPCC, 2007; Cole 2011; William et al., 2012). Zubairu (2012), states that the interface between a building's outdoor environment affected by climate change with its interior environment and the comfort required by its occupants is what makes it significant. As a result, when meeting the issues of climate change in recent days, professionals among different fields now pay more attention to the management and adjustment (Xuepeishan, 2016).

Studies (UKCIP, 2005; Robert and Kummert, 2012) showed that the domination of building built environment, as well as, connecting the built environment climate surrounding and its activities. Thus, understanding the study of the impact of climate change on the environment would provide a general scenario on building and vice-versa. Though the largely dependent on these impacts on; design, construction, use and location of buildings and building clusters (Liso et al., 2003). Studies also stressed that buildings consume a lot of energy leading to climate change (Schmidt et al., 2008; UNEP, 2009). Globally, buildings constitute a larger percentage of construction industry and tend to consume about $40-50 \%$ of energy (UNEP, 2009).

Recent major climatic disasters and their impacts on national and global economies have heightened awareness and spurred activities to improve the resilience of buildings recently (Stephen et al., 2014). According to Mona (2017) a changing climate presents a challenge to the planners and designers of the built environment. It is important to bear in mind that small increases in temperature above normal levels can increase hazards dramatically, including the intensity of cyclone wind speeds, bushfires and flash flooding (Mark and Deo 2011) which can lead to increase in building damage. An architect who designs for climate change adaptation (CCA) recognizes that the nature of weather events is unlikely to remain the same throughout a building's lifetime.

Edi and Edy (2018) argued that buildings are also important to the environment as showed in the quote below: "Building acts as a climatic modifier, separating the indoor built environment from the external climate described by the prevailing long-term weather conditions. The climate of a particular location tends to influence the shapes and forms of the local buildings and dictates the types of environmental control required. There is often a distinct correspondence between special architectural features and different climatic zones".

Edi and Edy (2018) argument shows the interrelationship importance between buildings and climate, because of how they influence the other and have direct and immediate environment impact. Globally, the different climatic regions reflected on the architectural design choices and practices. While numerous studies have suggested that buildings contribute to the causes of climate change (Wilby, 2007; Camilleri et al.2010; Berrang-Ford et al. 2011; Janda, 2011; Yi et al. 2016; Fanchao et al. 2017. Audrius and Arvydas (2017), they are, without doubt, affected by the 
impacts of climate change, hence affecting the functionality of buildings (Aliyu, 2010; Gething, 2011).

\section{Paradigm Shifts in Building Policies and Approaches as a Response to Climate Change}

The predictions of climate scenarios suggest regulatory/policy measures on climate adaptation should be taken as quickly as possible to avoid greater costs in the future (Stagrum et al., 2020). Buildings are affected by the physical impacts of climate variability and change. Consequently, countries all over the world are currently ensuring that buildings are climate resilient to reduce direct losses and reduce the indirect costs of disruption. The OECD in 2019 has cautioned that new building project should be planned, designed, built and operated to account for the climate changes that may occur over their lifetimes. The report further showed that existing building may need to be retrofitted, or managed differently, in view of climate change (OECD, 2020).

Aliyu, (2010) advised that building professionals (architects, planners, builders and engineers) need to work as team with climatologists/meteorologists in order to address the risks of climate change. Clearly, the built environment and its infrastructures have been noted to be vulnerable to climate change through higher temperatures, erratic and variable precipitation, rise in sea levels and wind actions, which have impacts on the surface of the environment and also varying impacts on the built environment.

Study by Liso et al (2003) aimed at providing an overview of the challenges of climate change impacts on the Norwegian built environment and how the country's climate policy can be used practically to confront and prepare for potential impacts. Their study found that technical regulations and standards were effective government tools for ensuring compliance to building design, construction and land-use, building locations and how buildings were clustered. In the case of Norway, they established; Building Research Design (which spells out solution-in-principle), which serves as design guide and must be monitored. Secondly, there is the need to regulate building locations through land use planning tools and land management, which will help curb the impacts of climate change on the built environment.

Gary and Patricia (2015) highlighted that discussions between industry and government policymakers in and beyond Ottawa, Canada about climate change and potential impacts on residential development regulations and corresponding industry practices. They advised that both private and public stakeholders must acknowledge the impacts of urban form on greenhouse gas (GHG) emissions, and, conversely, the impacts of climate change on cities, for any meaningful progress on urban sustainability to ensue.

A number of studies seeking solutions to the global effects and impacts of climate change on buildings have been carried out. Quite precisely is the housing sectorbased solution approach which was proposed by Schmidt et al. (2008) for developing countries as potential key to climate change mitigation framework. Another study by Adrián (2013) was concerned about the changing frequency and anxiety of Extreme Weather Events (EWEs), especially in poor developing countries, and the international community is progressively suggesting the design of adaptation funds to help the situation. Adrián (2013) noted that measures of vulnerability and submission to EWEs are a critical instrument in guaranteeing a transparent, economical and equitable allocation process in these funds.

John (2015) suggested that a new architectural sensibility should be based on the inputs of sunlight, daylight and air temperature in time and space at the early stages of design. Early but sound strategies can be tested and refined using advanced environmental modeling techniques. Architecture and environmental thinking can proceed hand in hand through the design process.

Nabil and Mahdi (2015) aimed at providing a platform of specialization for the construction management practitioners about the impacts of climate change on the construction projects' lifecycle, determine the most dangerous climate change factors on the construction projects' lifecycle, and analyze the most affected phase by climate change factors through the construction projects lifecycle. The study depended on the opinions of civil engineers, project managers etc., who have worked in the construction projects in the Gaza Strip. Questionnaire tool was adopted as the main research methodology in order to conclude the desired objectives. The questionnaire included 127 factors in order to obtain responses from 88 construction practitioners out of 98 representing $89.79 \%$ response rate about the impact of climate change on the generic lifecycle of construction projects.

Building professionals and designers will need to incorporate strategies that consider future climate change within their region (Mona, 2017). Similarly, Allu, (2014) pointed that building professionals need their own framework and tools for incorporating climate adaptation strategies in building projects.

\section{Climate Change Mitigation and Adaptation in the Building Sector}

Building professionals and environmentalist have shown that paradigm shift in building construction must be tailored towards climate change resistance. According to Turnbull, et al, (2020), for building to support the intergenerational health of our communities and living systems, rapid paradigm shifts is required in thought and action for everyone working in the design, construction, and procurement of our built environments.

Stagrum et al (2020) examined literature on climate adaptation measures for buildings through a scoping literature review. The study concentrated mainly on journals in the field of climate adaptation of the built environment, then expanded to map the extent of scientific publications about climate adaptation in general. Result showed that the majority of the identified literature was concerned with climate change impacts on buildings in warm climates, with overheating being seen as the greatest challenge. Additionally, few empirical studies are found; most identified research is based on computer simulations or literature reviews. The volume of research on the consequences of climate change on buildings in cold regions is surprisingly small, considering the peculiarities involved.

In terms of adapting buildings to flood, Claudia (2014), opined that flooding, coastal erosion, subsidence, drainage systems require new building techniques and materials in order to resist adverse weather conditions. 
Building a common floating "boardwalk," that connects the homes to one another, rises and falls with floodwaters and acts as the spine to which the houses connected has been designed as flood adaptive technique in residential buildings (Norwich Union and RIBA, 2008). The boardwalk creates a constant circulation network and serves as both a literal and symbollic expression of what people require in a time of crisis- access to one another. A raised foundation, shared by two buildings, creates a protected area above the prescribed flood level, on which vehicles and gardens are protected from floodwaters.

Niko et al., (2015) noted that environmentally responsible design features at each two-unit house serve both to reduce the development's environmental impact and to allow each house to sustain vital functions for its occupants during flood events. The paper further explained that empowering individuals allows neighbors to fight the effects of a flood together by sharing support and resources, strengthening and sustaining the sense of community.

Bello et al., (2017) lamented that the effect of major problem of flooding on the Nigerian built environment is that many existing buildings are mal-adapted and lacked defined adaptation strategy. In other words, the way they have been built increases their potential vulnerability to the flooding effects of climate change, especially the ones close to coasts. Thus, they formulated the general adaptation strategies to increase the ability of the built environment to adaptation of climate change flooding are as follow:

A strong need and emphasis on climate adaptation in planning policy, including action on coastal change and water resources are required. This must ensure that building design is done to be climate sensitive and conscious of high-risk areas through more stringent development control, building regulations must not only be set but must be enforced.

It has been advised that continuing investment in community-wide and property-level flood protection should be encouraged as steps to improve management of local flood risk. Planning policy should focus directly mostly on new development away from locations especially where it might flood in the coastal region or make resilient flooding to be safe (American Institute of Architects AIA, 2005).

Previous studies have suggested that trees would be planted for drought resilience, support cooling and drainage (Adger, 2005; Axel, et al., 2019; Biesbroek et al., 2020). The promotion of knowledge of homeowners and risk-reduction behavior through education and enlightenment has been seen as flood adaptation measures (Biesbroek et al., 2020). Axel, et al. (2019) also advised that individual homeowners can have a significant role in reducing risk through protecting their own homes and reducing their contributions of storm water to municipal sanitary sewers and storm water management systems.

The construction of built environment defenses to prevent and reduce the effect of flooding, raising of river banks and flood walls, creating sufficient storage reservoirs and canalization or channelization of flood passage and establishment of standard drainage system on roads have been suggested as adaption to flooding(Axel et al., 2019 ).
Though, construction of drainage is well documented as flood mitigation measure, Bello et al. (2017) emphasized that the design of drainage in an environmentally friendly way of dealing with surface water run-off that avoids the problems associated with existing drainage practice aims to reduce the potential impact of surface water drainage discharges in new and existing developments.

Agboola (2011) explained that thermal insulation is required in Northern Nigeria to prevent the heat of the hot tropical sun prevent the room interior from being unduly uncomfortable. This is resolved through the use of wide openings. This shows that the openings of the North and South walls should be large and preferably situated.

Passive design is a design that utilizes natural energy to moderate heat and achieves comfort. This is well acknowledged as adaptation measure for high temperature in residential buildings (Ortner, 2011; Lawal and Makinde, 2017). Ortner (2011) described architecture design passive solar energy for constructing comfortable interior environments by building with natural equipment, without using of mechanical equipment. According to Lawal and Makinde, (2017), all buildings are expected to be passive to the extents that without the use of mechanical systems driven by remote energy sources, all buildings should produce comfortable interiors climate.

Opoko, (2001) affirms that before selection of materials for this zone a good knowledge of thermal properties is required. The material which can minimize heat transfer into the building interior is required. These are basically materials, which are poor conductors of heat or have good reflective capacities. Thermal properties of building materials can further be enhanced by coating them with white and other colors which possess high reflective qualities.

Agboola (2011) explained the reason mud has been used indigenously for walls in hot Northern Nigeria, because of its resisting heat properties. Mud is a thick (heavy weight) material and has a very high heat storage capacity. It takes a considerable time to heat up and it takes long time as well to cool down again. It has a great advantage in hot dry regions, mainly because of temperature differences of the afternoon and the night. The heat absorbed slowly in the afternoon is dissipated slowly into the room interior warming it up at night. This zone should be heavy with high thermal capacity of walls, roofs and floors in a time lag of over eight hours.

Knowing about the wind direction of each region, bearing the most frequency from that direction (prevailing wind), is an important factor in setting the direction of building construction aerodynamically so that in the state of heavy winds, light buildings wouldn't be hit (Yazd and Kerman, 2012). Planting of windbreaks of trees on the prevailing windward side but well away from buildings has also been recommended (Spence, et al., 2018).

Zurich (undated) advised that, the roof and walls should be checked for damage after severe wind events. According to Zurich, effective measures that can help reduce a property's risk of wind damage such as:

i) Fitting glass windows and doors with storm shutters ii) Installing security mesh or robust, well-fitted insect screens on windows 
iii) Protecting skylights with mesh screens

iv) Reinforcing roller doors to withstand strong winds.

\section{RESULTS AND DISCUSSION}

Literally, there are serious rethink and reform on building sector in relation to climate change. Climate change has become the basis for building design and construction. There are strong links between climate change and building sector. However, while most studies reveal that climate change adversely affect building, a good number also argued that building construction is responsible for climate change mainly in terms of energy use and surface transformation/exposure. Though, there seems to be conflicting ideas on cause and effects between climate change and building construction. There is a general agreement that climate change affects the building sector. Scholars also agree on integration of climatic parameters, especially temperature and rainfall in building design, construction and use.

Climate change has become a basis for policy reform in building sector as many studies recommended knowledge and inclusion of climatic parameters in building planning, design, construction and use. Collaboration of climatologists and building professionals has become serious necessity in building policy reform. Climate adaptability, resiliency and sustainability have become the watchwords in qualifying built environment. Energy management in terms of sources and use are well noted in building reform as suggested by several studies.

Climate change mitigation and adaptation in the building sector varies among region along climatic regimes. Mitigation and adaptation of buildings to flood and extreme temperature are the common concerns of most studies. Raising of floor, use of local materials, orientation of building in accordance to sun and wind direction are among the mitigation and adaptation for building construction in the face of changing climate.

There is a handful of knowledge on the links between climate change and the building sector and paradigm shift is paramount in ensuring building sufficiency, performance, comfort and sustainability.

\section{CONCLUSION AND RECOMMENDATION}

There is handful information on the links between climate change and building sector and paradigm shift is paramount in ensuring building sufficiency, performance, comfort and sustainability.

Thus, improving building performance requires climate integration; literatures have shown that buildings are severely affected by climate change. Building sector have a huge role in Climate change mitigation and should be encourage by Government through training and policy reform.

Since building sector is a causal factor of climate change, adoption of climate change mitigation remedies in the building sector such as green building should be encouraged through training and incentives by Government. There is need for more researches on how to design and construct in line with local climates as climate varies among places.

\section{REFERENCES}

Adrián G., 2013. Climate Change and Extreme Weather Events in Latin America. Inter American

Development Bank. Research Dept. II. Title. III. Series IDB-TN-490.

Agboola O. P., 2011. Importance of climate to architectural designs in Nigeria. Journal of Environmental Issues and Agriculture in Developing Countries, 3(1).

Akanni Z. K., 2014. Road structures under climate and land use change Bridging the gap between science and application. PhD thesis submitted to Division of Land and Water Resources Engineering (LWR) Department of Sustainable development, Environmental science and Engineering Royal Institute of Technology (KTH) SE-100 44 STOCKHOLM, Sweden.

Aliyu S. B., 2010.Climate Change and the Building Industry in Nigeria. Researchgate publication.

Allu E., 2014. Climate Change and Buildings in Nigeria: A Search for Mitigation and Adaptation framework for Residential Design Guide.. A Thesis submitted to De Montfort University, Leicester, United Kingdom in Partial Fulfillment of the Requirements for the Degree of Doctor of Philosophy.

Adger W. N., 2005. Successful adaptation to climate change across scales. Global Environmental Change 15(2):77-86.

American Institute of Architects (AIA) 2005. Adaptation to Climate Change: Perspectives Across Scales. www.aia.org/practicing/research/index.htm Accessed 3/2/2018.

Audrius S. and Arvydas K., 2017. Estimation of climate change impact on energy consumption in a residential building in Kaunas, Lithuania, using HEED Software. Science Direct Energy Procedia 128 92-99, www.sciencedirect.com.

Axel C, Emilio B, Sophie P and Denis M., 2019. Vulnerability and costs of adaptation strategies for housing subjected to flood risks: Application to La Guérinière France. Marine Policy, Elsevier.

Bello N. A. Wasiu A. D. and Abdulkarim, R. I., 2017. Assessment of Adaptation Strategies to Flooding Impacts in Nigeria-A Review. Journal of Construction Engineering and Management.124: 361-373. 
Berrang-Ford, L. Ford, J. D. and Paterson, J., 2011. Are We Adapting to Climate Change? Journal of Global Environmental Change, 21:25-33.

Biesbroek, G. R. Swart, R. J. Carter, T. R. Cowan, C. Henrichs, T. Mela, H. Morecroft, M. D. and Rey, D., 2010. Europe Adapts to Climate Change: Comparing National Adaptation Strategies. Global Environmental Change, 20: 440-450.

Camilleri M and Jaques R., 2011. Climate change impacts on building performance. CIB World Building Congress, Building Research Association of New Zealand.

Camilleri M, Roman J and Nigel I., 2011. "Impacts of climate change on building performance in New Zealand", Building Research and Information, 29(6), 440-450.

Camilleri M, Jaques R and Isaacs N. (2010), "Climate change impacts on building performance", CIB World Building Congress, Building Research Association of New Zealand.

Claudia, K., 2014. Climate Change and the Construction Sector. International Investors Group on Climate Change (IIGCC) Briefing Note. 1-3.Climate and Development. Issue 63, Conflict, Political Geography 26(6): 674-694.

Cole, R. J., 2011. Motivating Stakeholders to Deliver Environmental Change www.iisbe.org/node/115.lCrawley, D. B. 2008. Impact of Climate Change on Buildings. https://www.cibse.org/pdfs/.

Emmanuel, R., 2009. Adaptation to Urban Climate Change through Design: Early Best Practices in the Tropics and Future Directions. CIB W108 Meeting, 26 March. Milan, Italy, Paolini E, (ed.), CIB Publication No. 325, pp. 7-11.

Emuze, F. A. Mgudlwa, N. P. and Botha, B., 2013. Architects' Perceptions of Biodiversity and Energy Efficiency in the city of Cape Town, South Africa. Proceedings of the SB13 Southern Africa Conference, 15-16 October, 2013. Cape Town- South Africa.

Edi. P and Edy D., 2018. Strategy of dwelling in the riverside settlement of the Arut River in Pangkalan Bun City, West Kotawaringin Regency, Central Kalimantan. IOP Conf. Ser.: Environ. Sci, 7(6).

Fanchao M, Mingcai Li, Jingfu C, Ji Li, Mingming X, Xiaomei F and Guoyu R., 2017.The effects of climate change on heating energy consumption of office buildings in different climate zones in China. Theoretical and Applied Climatology,www.researchgate.net.

Farajzadeh A. M., Gorbani A and Lashkari H., 2009. Analysis of Consistency of Sanandaj
Architecture Buildings with its Climate Condition in a Monthly Method. Lecturer Journal of Tarbiat Moddares University, No. 12, pp. 19-36.

Few, R. Brown, K. and Tompkins, E. L., 2007. Public Participation and Climate Change Adaptation: Avoiding the Illusion of Inclusion, Climate Policy, 7 (1), pp. 46-59.

Forzieri, G., 2018. Escalating impacts of climate extremes on critical infrastructures in Europe. Global Environmental Change, Vol. 48: 97-107.

Gary M and Patricia B., 2015. Climate Change and the Residential Development Industry in Ottawa Canada. CFICEOttawa, Ontario cfice@carleton.ca.

Gething, B., 2011. Design for Future Climate: opportunities for adaptation in the built environment Technology Strategy Board, UK.

Intergovernmental Panel on Climate Change. IPCC, 2007. Climate Change 2007. Impacts, Adaptation and Vulnerability. Contribution of Working Group II to the Fourth Assessment Report of the Intergovernmental Panel on Climate Change.

Janda, K. B., 2011. Buildings Don't Use Energy: People Do. Architectural Science, Review, 54(1):15-22.

John N., 2015. Climate Based Façade Design for Business Buildings with Examples from Central London. Buildings, 5:16- 38.

Lawal, A. and Makinde, F., 2017. Passive Solar Housing for Physiological Comfort in Warm Humid Climate. Unpublished Paper Delivered at the 1ST National Workshop of Faculty of Engineering, Osun State College of Technology, Esa- Oke, Held between 27th $-29^{\text {th }}$ November, pp 1-10.

Lawrence D., 2020. Hydrological projections for floods in Norway under a future climate. NVE. Norwegian Water Resources and Energy Directorate (NVE), Oslo, Norway.

Lashkari H., Pourkhadam N. Z., 2016. Optimization of Open Space Orientation in Ardabil based on Climate Conditions. Quarterly Geographical Research Journal, No. 20, pp. 19-36.

Lorenzoni, I. Nicholson-Cole, S. and Whitmarsh, L., 2007. Barriers Perceived to Engaging with Climate Change Among the UK Public and their Policy Implications. Global Environmental Change, 17, 445-459.

Liso, K. R., Aandahl, G., Eriksen, S and Alfsen, K., H., 2003.Preparing for climate Change impacts in Norway's built environment. Building Research and Information, 31(3). 
Mark S and Deo P., 2011. Climate Change Adaptation for Building Designers: An Introduction, EDG 66 $\mathrm{MSa} \cdot$ environmentdesignguide.com.au.

Ministry of the Environment and Food of Denmark / Environmental Protection Agency 2020. Climate change impact on buildings and constructions.

Mohammed N. A. and Gayan W., 2014. Making the Construction Industry Resilient to Extreme Weather: Lessons from Construction in Hot Weather Conditions. Procedia Economics and Finance 18: 635 - 642.www.sciencedirect.com.

Mona El. B., 2017. Resilient Buildings: A Path towards Adaptability Climate Change Adaptation Strategies and Interventions for Buildings Resilience. International Journal of Current Engineering and Technology,7 (2).

Nabil E and Mahdi M.(2015). Influence of Climate Change on the Lifecycle of Construction Projects at Gaza Strip. KICEM Journal of Construction Engineering and Project Management 4(3).

Niko H, Christopher L, Bernhard S, York O, Holger W and Stefanie H., 2015. Environmental Impact of Buildings -What Matters? Environ. Sci. Technology, 49(16):9832-9841.

Norwich Union and RIBA., 2008. Flood-proof houses for the future: A compendium of design. Retrieved online at https://wwwdotejarchitectdotcom.files.wordpress .com /2014/01/floodproof-houses-of-thefuture.pdf.

Organization for Economic Cooperation and Development OECD, 2019. Integrating Climate Change Adaptation into Development Cooperation: Policy Guidance, OECD Publishing, Paris.

Onkangi N. R., Mwangi P. N., Erick M. and Ondari L., 2018. Vulnerability and Adaptation Levels of the Construction Industry in Kenya to Climate Change. Handbook of Climate Change Resilience pp 1-18.

Opoko, A. P., 2011. Low energy features of traditional buildings in the hot dry climatic zone of Nigeria. The Nigeria Institute of Architects Journals 11 (8), 12, 29- 35.

Ortner, E. H., 2011. Natural Ventilation. Windows and Class in the Exterior of Buildings. Washington, D. C. Building Research Institutes.

Robert, A. and Kummert, M., 2012. Designing net-zero energy buildings for the future climate, not for the past. Building and Environment, 55, 150158.
Schmidt, J. Helme, N. Lee, J. and Houdashelt,V., 2018. Sector-Based Approach to the Post-2012 Climate Change Policy Architecture. Climate Policy 8, pp. 494- 515. www.climatepolicy.com.

Spence, R J S, Fawcett W H and Brown A .J., 2018. The windstorm vulnerability of the UK building stock. Proceedings of the 4th UK Conference on Wind Engineering, Bristol, 2-4 September.

Stephen S. Szoke, L and John O., 2014. National Institute of Building Sciences, Washington, DC.LEED/AP, CSI-CDT.

Turnbull G, David C and Jessica P., 2020. Manifestos on the Climate Crisis. Canadian Architect.

Stagrum A. E., Andenses E. Kvande and Lohne J., 2020.sustainability review climate change adaptation measures for buildings- A scoping review.

Ugochukwu S. C, Iheama, N. B., and Onyejiaka, J. C., 2020.influence of climate change on building design in Enugu South L.G.A of Nigeria.

UK Climate Impacts Programme UKCIP, 2005. Thinking climate. www.ukcip.org.uk (Accessed 18/01/2019).

Umoh, U. T. (2000). Environmental Parameters and Effective Housing in Nigeria. Effective Housing in 21st Century Nigeria, Environmental forum, Federal University of Technology, Akure. Pp $145-149$.

United Nations Environment Programme UNEP, 2009. Buildings and Climate Change Summary for Decision Makers. UNEP Sustainable Buildings and Climate Initiative (SBCl).

Wilby, R. L., 2007. A Review of Climate Change Impacts on the Built Environment. Built Environment, 33(1): 31-45. Alexandrine Press, 33(1):3145.Alexandrine Press.

Williams, D. Elghali, L. Wheeler, R. and France, C., 2012. Climate Change Influence on Building Lifecycle Greenhouse Gas Emissions: Case Study of A UK Mixed-Use Development. Energy and Buildings, 48, 112-126. International Journal of Contemporary Applied Sciences, 2 (5).

Xuepeishan C., 2016. An Analysis of Climate Impact on Landscape design. Atmospheric and Climate Sciences, 6: 475-481.

Yi Z. K. Yan, Tao C, Quan Z, Liping Q and Shan W., 2016. Influence of Climate Change in Reliability Analysis of High Rise Building. Mathematical Problems in Engineering, Volume 20.

Zareaian, S and Zadeh.K. A., 2013. the Role of Climate Factors on Designing and Constructing 
Buildings (From Urbanization Architecture Approach). Bull. Env. Pharmacol. Life Sci., Vol 3 (1): 197-200.

Zubairu, S., 2012. The importance of evaluation and sustainability in the built environment In: Laryea, S. Agyepong, S. Leiringer, R. and Hughes, W. (Eds) Procs 4th West Africa Built Environment
Research (WABER) Conference, 24-26 July 2012, Abuja, Nigeria, 9-13.

Zurich. (undated). Storm-proofing your propertyreducing your risks. Published by Zurich@https://www.zurich.com.au/brokers/tools -and-insights/risk-reduction. 